\title{
Editorial
}

\section{Moral Emotions and Moral Cognitions}

In the novel "létranger" written by Albert Camus (1942), the character Meursault is introduced as being a stranger within society, as being provocatively indifferent towards moral norms, lacking compassion or strong moral judgment, but is rather driven by sensational experience. What is it that makes us judge this character as immoral? Is it his lack of moral sensitivity, or his lack of poignancy in moral judgment, or his general nihilistic outlook on life?

This question of how to define morality has been debated across the disciplines for centuries. While some theorists have argued that moral judgment is the foundation of morality (Kant, 1785/1959; Kohlberg, 1984), others have identified emotions (Smith, 1759/1976; Hoffman, 1982) or intuitions (Haidt, 2001) as the basis of human morality. Over the last years the debate on morality has been increasingly stimulated by research outside the domain of developmental psychology, spanning from the cognitive and social sciences to neuroscience and economics (see the three volumes edited by Sinnott-Armstrong, 2008, for an overview).

The present issue aims at sheding light on this debate and discussing the question of how to understand the role of moral emotions and moral cognitions in human morality within the context of developmental science. Developmental science provides an integrative, holistic framework for this debate, because it takes a comparative perspective and tries to bridge the levels of explanation, spanning from ecological systems to brain development, in order to understand morality in ontogenesis (cf. Bergman, Cairns, Nilsson, \& Nystedt, 2000; Bronfenbrenner \& Evans, 2000).

Against this background, this issue presents interdisciplinary perspectives on the study of moral emotions and moral cognitions, ranging from philosophy and sociology to cultural and developmental psychology to neuroscience to scrutinize the questions of how to define morality and how to understand its core components.

The first article by Gummerum and Keller (2008) explores the innovative interconnections between moral psychology and economic game theory. The authors argue that adopting a game theoretical perspective would provide a novel methodology for investigating the moral development of children, especially as the game theoretical approach has become an interdisciplinary paradigm that has been neglected in developmental psychology of morality. Reversely, developmental psychologists can contribute their knowledge about the ontogenesis of moral abilities to economic research.

The second article by Krettenauer, Malti, and Sokol (2008) critically reviews the basic and applied literature on moral emotion expectancies and propose an integrative view on emotions and cognition. They argue that the growing coordination between moral emotion expectancies and moral judgments is a key element in the evolving moral identity that critically impacts social adaptation across the life-span. 
In the third article, Miller, Chakravarthy, and Das (2008) present a cross-cultural perspective on moral emotions. The assumption of an inverse relationship between the moral emotions of guilt and satisfaction in regard to prosocial behavior as formulated in major theories of moral psychology is shown to be less oppositional in collectivist than in individualistic cultural settings.

In the fourth article, Nunner-Winkler (2008) describes a socio-historic perspective on changes in the structure of moral motivation, as a partially independent dimension of moral reasoning. By drawing on the theory of civilization by Norbert Elias, Nunner-Winkler points out that both, cognitive and motivational moral development change with changing societal structures and socialization styles.

The fifth article from Graham, Haidt and Rimm-Kaufman (2008) proposes that social psychology research has presented broad evidence for intuition as a central component of morality. Moral intuitions include affective and cognitive components, and the authors elaborate the importance of these intuitions for moral education. A theory of intuitive ethics is introduced, which is conceptualized as a normative basis for moral education despite different educational ideologies.

In the sixth contribution, Kasachkoff and Saltzstein (2008) present a critique of the social-intuitionist model from a philosophical perspective. According to the authors, the social-intuitionist model simplifies the relationship between moral judgment and moral reasoning, ignores research concerning the influence of persuasion on social influence and puts too much emphasis on the genetic and evolutionary basis of morality compared to a cognitive-reflexive component.

The seventh contribution from Blair and Fowler (2008) provides a selective review on moral emotions and moral reasoning from the perspective of affective cognitive neuroscience. The authors consider the role of two interrelated neuro-cognitive components that are implicated in the moral emotions of guilt, embarrassment and shame and show that the activity of these regions suggests a critical role for emotion in moral reasoning.

The issue concludes with an article by Smetana and Killen (2008) presenting an integrative developmental view on moral cognition, emotion, and neuroscience. Drawing on different lines of research, a theory of morality is supported in which moral cognition is central and in which emotions are used to interpret morally relevant situations. The authors infer that defining morality as moral judgment remains the fundamental basis of human morality.

By contrasting diverse perspectives on the role of moral emotions and moral cognitions in human moral functioning, we believe that this issue contributes to advancing our understanding of moral development. In future research, integrative approaches to human morality seem promising avenues to shed further light on our understanding of it. 


\section{References}

Bergman, L.R., Cairns, R.S., Nilsson, L.-G., \& Nystedt, L. (2000). Developmental science and the holistic approach. Mahwah: Lawrence Erlbaum.

Blair, R. J. R., \& Fowler, K. A. (2008). Moral emotions and moral reasoning from the perspective of affective cognitive neuroscience: A selective review. European Journal of Developmental Science, 2, 303-322.

Bronfenbrenner, U., \& Evans, G.W. (2000). Developmental science in the 21st century: Emerging questions, theoretical models, research designs and empirical findings. Social Development, 9(1), 115-125.

Camus, A. (1942). Létranger. Paris: Hatier.

Graham, J., Haidt, J., \& Rimm-Kaufman, S. E. (2008). Ideology and intuition in moral education. European Journal of Developmental Science, 2, 269-286.

Gummerum, M., \& Keller, M. (2008). Moral psychology and Economic Game Theory. European Journal of Developmental Science, 2, 206-220.

Haidt, J. (2001). The emotional dog and its rational tail. Psychological Review, 108, 814-834.

Hoffman, M. (1982). Development of prosocial motivation: Empathy and guilt. In N. Eisenberg (Ed.), The development of prosocial behavior. New York: Academic Press.

Kant, I. (1959). Foundations of the metaphysics of morals. New York: MacMillan (Originally published 1758).

Kasachkoff, T., \& Saltzstein, H. D. (2008). Reasoning and moral decision-making: A critique of the Social Intuitionist Model. European Journal of Developmental Science, 2, 287-302.

Kohlberg, L. (1984). The psychology of moral development: The nature and validity of moral stages. San Francisco: Harper and Row.

Krettenauer, T., Malti, T., \& Sokol, B. W. (2008). The development of moral emotion expectancies and the Happy Victimizer Phenomenon: A critical review of theory and application. European Journal of Developmental Science, 2, 221-235.

Miller, J. G., Chakravarthy, S., \& D. R. (2008). The moral emotions of guilt and satisfaction: A cross-cultural perspective. European Journal of Developmental Science, 2, 236-250.

Nunner-Winkler, G. (2008). From super-ego and conformist habitus to ego-syntonic moral motivation. Sociohistoric changes in moral motivation. European Journal of Developmental Science, 2, 251-268.

Sinnott-Armstrong, W. (Ed.) (2008). The evolution of morality. Cambridge: MIT Press.

Sinnott-Armstrong, W. (Ed.) (2008). The cognitive science of morality. Cambridge: MIT Press.

Sinnott-Armstrong, W. (Ed.) (2008). Morality in the brain. Cambridge: MIT Press.

Smetana, J. G., \& Killen, M. (2008). Moral cognition, emotions, and neuroscience: An integrative developmental view. European Journal of Developmental Science, 2, 324-349.

Smith, A. (1976). The theory of moral sentiment. Oxford: Oxford University Press. (Original work published 1759).

Tina Malti

Michaela Gummerum

Monika Keller 